\title{
HOW CAN LOCAL GOVERNMENTS LEVEL THE SOCIAL GRADIENT IN HEALTH AMONG FAMILIES WITH CHILDREN? THE CASE OF NORWAY
}

\author{
Elisabeth Fosse and Marit K. Helgesen
}

\begin{abstract}
The Norwegian National government has recently developed policies to reduce health inequalities; this should be achieved by a Health in all Policies approach (HIAP). Most policies are to be implemented at the local level and municipalities are responsible for the implementation. The aim of this paper is to answer this question: How can municipalities reduce social inequalities and among families with children through a mixed methods approach, using surveys as well as qualitative interviews in the collection of data? The main conclusion is that they are in different places when it comes to implementing public health and health promotion policies. The responsibility for public health and health promotion is to a large degree still left to the health sector, including those in positions as public health coordinators. To achieve HIAP, these positions should have an executive function in order to coordinate and influence local policies using a combination of universal and targeted measures. However, no extra funding has been allocated via the national budgets, and intensified efforts are still funded via projects. Still, we observe a change towards increased awareness of the HIAP approach to reduce social inequalities.
\end{abstract}

Keywords: Norway, policy, municipalities, levelling the gradient, families

Acknowledgments: The research presented in this paper is funded by the Norwegian Research Council projects "Addressing the social determinants of health: Multilevel governance of policies aimed at families with children” (Project no.213841/H10) and "Evaluation of the Coordination Reform: Impact of the reform on health promotion and disease prevention in municipalities” (Project no. 229628). The research is also built on the project "Health Promotion and Prevention" funded by the Norwegian Association of Municipalities and Counties.

Elisabeth Fosse, Ph.D. is a Professor in the Department of Health Promotion and Development, University of Bergen, Christiesgate 13, 5015 Bergen Norway. E-mail: Elisabeth.Fosse@hemil.uib.no

Marit K. Helgesen, Ph.D. is a Dr. polit., and Senior Researcher, Norwegian Institute for Urban and Regional Research, Gaustadalléen 21, 0349 Oslo. E-mail: marit.helgesen@nibr.no 
Norway is a Scandinavian nation with a rather small population of 5.1 million. Over the last 30 years the country has become increasingly wealthy as a result of its growing oil economy. Norway is one of the so-called social democratic welfare states, as classified by Esping-Andersen (1990). The "social democratic" regime is characterized by its emphasis on solidarity and universalism, and the redistribution of resources among social groups, mainly through a progressive tax system and entitlements to vulnerable groups. This is a system of emancipation, not only from the market, but also from the family (Esping-Andersen, 2009). The result is a welfare regime with direct transfers to families and children and one which takes direct responsibility for the care of children, providing services that enable women with families to engage in paid work.

While there may be lack of agreement on what policy measures are necessary in order to reduce social inequalities in health among families with children, researchers have suggested the following measures (Östergen \& Barnekow, 2007; Marmot, 2007; Lundberg, 2009):

- Increasing quality of life and reducing social inequalities among children will demand resources. Countries need to spend more resources on children and families to reduce inequalities.

- It is necessary to carry out comprehensive, intersectoral action.

- It is also necessary that comprehensive, intersectoral policies must be combined with targeted measures aimed at disadvantaged and vulnerable children and families.

- Macro-level policies, in terms of universal and generous welfare policies, will provide a social safety net and promote the health of children and families.

There is an overall recognition that policies developed in other sectors than the health care sector play an important role for the health of the population. Policies to keep children and families out of poverty and ill-health include: labour market policies; cash benefits; child care; access to education; participation in culture, sport, and recreation; access to decent housing and safe neighbourhoods; access to health care; and access to social services (Ministry of Labour and Social Inclusion, 2006).

Countries with a policy structure reflecting the social democratic welfare state regime are most likely to have policies in place to support families with children. A vital point seems to be the fact that family policies are an important feature of these regimes. Policies like generous parental leave and affordable child care of good quality represent supports to dualearner families in general, but also provide single parents with a safety net that prevents them from falling into poverty (Fosse, Bull, Burström, \& Frtitzell, 2014). These welfare states also are highly decentralized as municipalities provide most welfare services (Sellers \& Lidstrøm, 2007).

Over several years Norway has been ranked at the top of the United Nations Human Development Index. However, even though the overall picture of Norway is a positive one, the country still has its challenges. Social inequalities in health are increasing. For example, more children now than 10 years ago live in families with persistently low income (Dahl, Bergsli, \& van der Wel, 2014; Fosse, 2013). These children are more exposed to air pollution in neighbourhoods and poorer air quality in their homes than other children; they take part in sports and other leisure activities less often than others; and their families are more isolated and considered to have less social capital than other families (Kjelvik, 2012). This implies 
that relative health inequalities in Norway are not smaller than in other European countries (Popham, Dibben, \& Bambra, 2013).

The Norwegian National government has recently developed policies to reduce health inequalities (Directorate of Health, 2010, 2012). Most policies are to be implemented at the local level and municipalities are responsible for providing the overall bulk of welfare services. In this paper we ask whether or not municipalities are acting in concert with the central government in implementing policies to reduce social inequalities in health. Does the national policy impact on the priorities of the municipalities regarding policies that distribute services for families with children? How do the municipalities act to reduce social inequalities and level the social gradient in health? We answer these questions by first presenting the new Norwegian Public Health Act, which provides the basis for policies to level the gradient among families with children. Secondly, we look at the Norwegian governance system. Thirdly, we present recently gathered quantitative and qualitative data on local government implementation of such policies. Lastly, we discuss the impact of the policies for families with children.

\section{The Public Health Act}

A new Public Health Act (PHA) ${ }^{1}$ was introduced in Norway January 1, 2012 (Ministry of Health and Care Services, 2011). The Act establishes a new foundation for strengthening systematic public health work and developing policies and planning for societal development based on regional and local challenges and needs. The PHA provides a broad basis for the coordination of public health work horizontally across various sectors and actors and vertically between authorities at local, regional and national levels. In the intention underlying the Act it is stated that: Only by integrating health and its social determinants as an aspect of all social and welfare development through intersectoral action, can good and equitable public health be achieved (Ministry of Health and Care Services, 2011).

The PHA underlines that health inequities arise from the societal conditions in which people are born, grow, live, work, and age - the social determinants of health. Furthermore, it is stated that social inequities in health form a pattern of a gradient throughout society.

Levelling up the gradient by action on the social determinants of health is a core public health objective and it is stated that fair distribution of societal resources is good public health policy. The principle of Health in All Policies (HIAP) implies that equitable health systems are important to public health, but health inequities arise from societal factors beyond health care (Leppo, Ollila, Peña, Wismar, \& Cook, 2013; Melkas, 2013). As stated by Ståhl, Wismar, Ollila, Lahtinen, and Leppo (2006), the Health in All Policies principle addresses the effects on health across all policies such as agriculture, education, the environment, fiscal policies, housing, and transportation. It seeks to improve health and at the same time contribute to the well-being and the wealth of nations through structures, mechanisms, and actions planned and managed mainly by sectors other than health. This implies that the impact on health must be considered when policies and action are developed and implemented in all sectors.

Intersectoral action is regarded as key to reduce health inequities. The PHA embraces the idea of "Health in all policies". In governance terms, one of its main features is that it

\footnotetext{
${ }^{1}$ The Norwegian term "Folkehelse” has a wider connotation than the English term "Public Health" as it includes both traditional public health practice and health promotion.
} 
places public health work as a whole-of-government and a whole-of-municipality responsibility rather than a responsibility for the health sector alone. In public health work the municipalities should involve all their sectors and all corresponding units providing services for the promotion of public health, not just their health sector. A particular focus is on having the local planning system serving to ensure that the overall aims of the policy are being implemented. At the national level the PHA is coordinated with the Planning and Building Act (PBA) in which one of the goals is stated as: contribute to reduce social inequalities in health (PBA § 1). This means that the broad determinant perspective in the PHA is to be the foundation for local government planning (Hofstad, 2011). An overview of public health and health determinants constitutes the starting point for evidence-based public health work. All local governments must develop an overview of the population's health status and determinants that influence health and disease in the population. The overview should identify local health challenges and their determinants combined with a specific focus on social inequalities in health.

Based on local assessments of the public health challenges, public health policy development must be integrated into ongoing societal and spatial planning and administration processes in counties and municipalities, as well as part of other social development strategies. To initiate the overview and ensure coordination among local government units providing services, municipalities are advised to employ a public health coordinator.

\section{The Norwegian Governance System}

The Norwegian governance system may be characterized as decentralized and multilevel (Hanssen \& Helgesen, 2011). A total of 428 municipalities have the overall responsibility for welfare provision, including services such as preschools, schools, child care, and care for the elderly, social support and services, primary health care, culture, agriculture and social development in local areas; this includes the development of industry and jobs (Tallarek, Helgesen, \& Fosse, 2013). Norwegian municipalities have a dual role. On the one hand, they are agents for the welfare state through their responsibility for implementing national policy goals. On the other hand, they form independent local democratic arenas that decide how to use national funding in accordance with local preferences and needs (Baldersheim \& Ståhlberg, 2002). These needs vary to a great extent as Norwegian municipalities strongly differ with regard to size - their populations range from 200 to 600,000 , the average being a little over 10,000 . They also vary regarding resources, geographical conditions, and infrastructure, as well as their political and administrative organization (Ministry of Local Government and Regional Development, 2012).

The term "multi-level” pertains to the changed role of municipalities in the centrallocal relationship. Thus, a shift in governance can be observed towards a more egalitarian relation between actors across sectors and levels of formal authority. This may be considered as being necessary in order to reach political objectives, as the National government cannot reach its ambitions without taking the opinions and interests of actors at lower levels into consideration (Sørensen \& Torfing, 2005, 2007). This implies that the traditional forms of hierarchical government have been decoupled. Centralized leadership is no longer carried out through a detailed hierarchical system of sanctioned rule but rather is increasingly taking place through more indirect regulation with the assumption that actors are self-regulating (Sørensen and Gjelstrup, 2007). The relationship between institutions at different levels of government is held to be increasingly fluid, negotiated, and contextually defined. This trend 
has often been denoted as multi-level governance, understood as a system of continuous negotiation among nested governments at several territorial tiers (Hooge \& Marks, 2004). The governance practices, targets, procedures, steering instruments, and distributional mechanisms are illustrated in the figure below.

Figure 1: Governance practices (Osborne, 2010)

\begin{tabular}{|l|l|l|l|l|}
\hline $\begin{array}{l}\text { Governance } \\
\text { practices }\end{array}$ & Targets & Procedures & $\begin{array}{l}\text { Steering } \\
\text { instruments }\end{array}$ & $\begin{array}{l}\text { Distributional } \\
\text { mechanisms }\end{array}$ \\
\hline $\begin{array}{l}\text { Public } \\
\text { Administration }\end{array}$ & $\begin{array}{l}\text { Policy formulation and } \\
\text { implementation } \\
\text { (content) }\end{array}$ & $\begin{array}{l}\text { Decision- } \\
\text { making, } \\
\text { planning }\end{array}$ & $\begin{array}{l}\text { Financial, legal } \\
\text { regulations }\end{array}$ & $\begin{array}{l}\text { Hierarchy, } \\
\text { command, and } \\
\text { control }\end{array}$ \\
\hline $\begin{array}{l}\text { New Public } \\
\text { Management }\end{array}$ & $\begin{array}{l}\text { Management of } \\
\text { resources and } \\
\text { performance (results) }\end{array}$ & $\begin{array}{l}\text { Strategic } \\
\text { management, } \\
\text { output control }\end{array}$ & $\begin{array}{l}\text { Supervision and } \\
\text { audit }\end{array}$ & $\begin{array}{l}\text { The market or } \\
\text { market-like } \\
\text { mechanisms }\end{array}$ \\
\hline $\begin{array}{l}\text { New Public } \\
\text { Governance }\end{array}$ & $\begin{array}{l}\text { Negotiation of values, } \\
\text { meanings, and } \\
\text { relationships } \\
\text { (processes) }\end{array}$ & $\begin{array}{l}\text { Designing, } \\
\text { framing, and } \\
\text { guiding } \\
\text { networks }\end{array}$ & $\begin{array}{l}\text { Networking, } \\
\text { negotiations }\end{array}$ & $\begin{array}{l}\text { Networks and } \\
\text { relational } \\
\text { mechanisms }\end{array}$ \\
\hline
\end{tabular}

These governance practices have changed over time. The national institutional context shapes the administrative framework and the organization of policies and services at all administrative levels. Procedures involve decision-making and planning, while the steering instruments are mainly financial and legally binding. The distributional mechanisms are hierarchical command and control. As in many other countries, the principles often referred to as the "New Public Management" (NPM) were introduced in Norway during the 1980s. Management by objective was institutionalized in the state-local relation by the implementation of the Act on Local and Regional Governments in 1992 (Ramsdal \& Skorstad, 2004). However, national steering ambitions have not disappeared. As a consequence, the complexity in steering and regulation has increased. The governance practices of management and negotiation allow municipalities to interpret and translate policies to accommodate them to their own circumstances and priorities (Helgesen \& Hofstad, 2014).

In the PHA, all three governance practices outlined above come into play. Hierarchical governance is identified by more regulations and corresponding guidelines. Management manifests itself as the audits performed by the National government, via the county governors. The county governor is responsible for overseeing that municipal plans are followed up. The municipal master plan is the committing document, which must comply with national laws and regulations. Furthermore, the network governance mechanisms are obvious as municipalities must collaborate closely with regional government, other relevant actors, and accommodate intersectoral cooperation among local government units providing services. Municipal income is provided through economic transfers, consisting of general grants from the National government, and carried out as a formula budget system. No earmarked funds 
have been allocated to the municipalities for the implementation of the PHA. Some funding is available to target particular priorities but these are mostly for time limited projects and programs (Helgesen et al., 2014).

Within this complex framework of multilevel procedures, local governments implement policies to promote health and level the social gradient. In the following we will discuss whether or not local governments establish policies and practices in concert with national policy ambitions.

\section{Methods}

The article is based on a mixed methods approach, using surveys as well as qualitative interviews in the collection of data. Two surveys of Norwegian local governments were carried out. A baseline study was conducted in 2011, a few months before the PHA was implemented. In 2011 there were 430 municipalities and the 15 partly self-governing urban districts of Oslo. The survey was sent to the chief executive officers in municipalities and urban districts who either answered the survey themselves or passed it on to an appropriate employee to answer. A total of 361 municipalities and urban districts filled in the questionnaire, which gave a response rate of $87 \%$. The smallest and most remote municipalities were the ones that in most cases did not respond (Helgesen \& Hofstad, 2012). The second survey was carried out in spring 2014. As with the first, it was sent to chief executive officers in municipalities and urban districts of Oslo, and 303 units responded. The response rate was $73 \%$. Again this time, the smallest and most remote municipalities did not respond to the survey. Focus group interviews were conducted in six municipalities. Inclusion criteria were that municipalities had worked to implement the PHA policy - planning, intersectoral collaboration - and had a focus on social inequalities. Among these, we created a convenience sample building on distance and time of travel to the nearest centre. The chosen municipalities had worked in partnership with their respective counties and they all described this as important in both raising consciousness about the importance of public health and having the support and the facilitating role of the county administration. When quotations from municipalities are provided, they are numbered subsequently from one to ten.

\section{Findings}

The Norwegian Public Health Policy provided a main focus on comprehensive, intersectoral strategies several years before the PHA was launched (Fosse, 2009, 2012, 2013; Strand \& Fosse, 2011). On this basis, it could be expected that the policies had been adopted by the municipalities. However, the 2011 study showed that the municipalities had only to a small extent adopted the principles of the new public health policy (Helgesen \& Hofstad, 2012, 2014; Tallarek et al., 2013). The findings identified a divide between the national policies and the strategies adopted at the municipal level to implement these public health policies. Many municipalities focused mainly on measures related to lifestyle and health care. The Health in All Policies perspective was present only to a limited extent, as only a few municipalities had acknowledged the social determinants of health and had implemented intersectoral strategies to level the social gradient in health. At the time, few municipalities had started to develop health overviews. In the 2014 survey we wanted to check whether this was still the situation or if local governments now comply more with national policies. 


\section{Planning and health overviews}

The Norwegian Public Health Institute provides the local governments with statistical data on the health situation of their citizens. Variables on various determinants of health are included in the overviews, as for example the number of unemployed, number of singleparent households, and how many children and youth feel that they are bullied at school. Municipalities are to complete these overviews with knowledge of local determinants that they, among others, gather from their service-providing agencies. This would typically include the number of children receiving child welfare, the status of their housing policies, how local governments consider the child environments according to schools, kindergartens, and outdoor recreation, and their need for professional employees in various fields of service provision. The overviews should be used as a basis for planning, and for the development of measures to meet documented health challenges in the population. Such overviews were identified as important by the PHA. When we asked municipalities in 2011, only $13 \%$ had developed an overview and by 2014, 24.5\% had completed one.

Local governments are mandated to develop several plans. Such plans are first and foremost the Land Use Plan and the Long-term Plan on economic prioritization; the Master Plan, and the Short-term Action Program (Hofstad, 2011). Also thematic plans can be used to put certain themes on the local government agendas. In land use plans, local governments allocate land to different aims according to local development, and this plan is legally binding (Fallet \& Saglie, 2013). In 2011 we asked if the municipalities had integrated one public health theme or more into their local plans. How municipalities included certain themes in their plans in 2011 is shown in Table 1.

Table 1

Inclusion of Public Health Themes in Local Government Plans in 2011, in Percentages with Numbers in Parentheses. $N=284$

\begin{tabular}{|l|l|l|l|}
\hline Plan type / Theme & $\begin{array}{l}\text { Land Use Plan } \\
(\%)\end{array}$ & $\begin{array}{l}\text { Long-term Master } \\
\text { Plan (\%) }\end{array}$ & $\begin{array}{l}\text { Short-term Action } \\
\text { Program (\%) }\end{array}$ \\
\hline $\begin{array}{l}\text { Green and recreational } \\
\text { areas }\end{array}$ & $34(95)$ & $33(93)$ & $15(43)$ \\
\hline Universal design & $21(59)$ & $34((95)$ & $14(43)$ \\
\hline Housing & $19(55)$ & $38(109)$ & $26(75)$ \\
\hline Child environments & $13(38)$ & $48(136)$ & $27(77)$ \\
\hline Physical activity & $10(27)$ & $40(121)$ & $22(62)$ \\
\hline Kindergartens & $9(26)$ & $34(97)$ & $32(84)$ \\
\hline
\end{tabular}

Green and recreational areas score the highest among the public health themes in the Land Use Plans, while child environments scores highest in the Master Plans and kindergartens in the Action Program. We can, however, conclude that a plethora of themes are included in plans, and many of them are relevant to public health even though an overview of the local health situation had not been developed (Helgesen \& Hofstad, 2012). In 2014 we 
asked how many municipalities had used the overview as a basis to establish priorities between policies, and $12 \%$ out of 282 answered yes to this question. About $12 \%$ had used the overview to prioritize in their Action Program and 4\% in their Master Plan.

In Municipality 4 the public health coordinator spoke of the overview and planning in the following way:

My approach to the overview will be based on my background as a land use planner. What do we have and what do we need? And then include it in plans and structure it [the knowledge and the prioritized measures derived from the knowledge]. And it involves all political committees, all minor municipal councils, the executive committee and the elected municipal council. (Municipality 4)

Prioritized measures were, among others, directed at school dropouts, immigrant citizens, and children. In Municipality 5 the focus group contended that:

We are about to update our Land Use Plan. It will be very exciting to see if we are able to anchor health promotion in the plan. .... It is to acknowledge that physical environments, the accommodation made by integrating it into the Land Use Plan is important to, for instance, lower the threshold for physical activity. ... Short distances, walking distance, bicycle distance, and the possibility to establish a network of walking and bicycling roads to accommodate leisure as well as school and job travels [is important]. (Municipality 5)

To achieve these goals, local planning officers will need to have in-depth knowledge about their local area, as for instance where different groups of people such as older persons, children, and youth live and what are the smartest routes to get to schools and jobs.

Health in All Policies require intersectoral collaboration at both the policy and service levels. The overview of health determinants and the integration of health in planning are not the only indicators of the extent of a local Health in All Policies approach.

The extent to which municipalities have established intersectoral working groups is also vital. In 2011, 95\% of 316 municipalities had established such groups. In 2014 the number of municipalities ( $n=281$ ) who answered yes to this question was reduced to $62 \%$. Furthermore, whether service-providing agencies are involved in such groups is an indicator of intersectoral collaboration. Table 2 shows these trends. A third indicator is whether or not municipalities have employed a public health coordinator. In 2011, 74\% of 347 municipalities had employed a coordinator. In 2014, $85 \%$ out of 307 municipalities had done so. The fourth indicator is the organizational location of the coordinator. This last indicator is displayed in Table 3.

Even though there were fewer municipalities reporting on having established intersectoral working groups in 2014, there is an increase in the reported number of municipal service-providing agencies involved in such groups. This is displayed in Table 2. 
International Journal of Child, Youth and Family Studies (2015) 6(2): 328-346

Table 2

Municipal Service-providing Agencies Involved in Intersectoral Work Groups on Health Promotion, in Percentages with Numbers in Parentheses. $N=2011: 301$; 2014:175

\begin{tabular}{|l|l|l|}
\hline Year / agency taking part & $2011^{*}$ & $2014^{* *}$ \\
\hline Child health centre/School health service & $82(259)$ & $81(142)$ \\
\hline Culture/sports & $74(233)$ & $68(119)$ \\
\hline Schools & $69(209)$ & $75(132)$ \\
\hline Mental health & $67(201)$ & $41(71)$ \\
\hline CEO staff & $56(176)$ & $69(120)$ \\
\hline Child care & $36(114)$ & $41(72)$ \\
\hline Kindergartens & $55(174)$ & $50(88)$ \\
\hline Plan/environment/technical & $17(50)$ & $65(114)$ \\
\hline
\end{tabular}

*In 2011 respondents were asked to answer to a great extent, to some extent, not taking part, and do not know. Those answering to a great and some extent are included.

** In 2014 respondents were asked to answer yes, no, do not know. Both years more answers were possible.

These findings give a picture of which service-providing units are involved in intersectoral working groups. For most units there is a decrease in intersectoral collaboration. For the schools, the CEO staff, and the planning department, there is an increase. For the planning unit there is also an increase in absolute terms. For both years the child health centres and the school health services are most involved in intersectoral work groups, as well as in culture, sports, and schools. These are the units most associated with health promotion in municipalities and the ones with the longest traditions of carrying out such work.

Schools are more involved in 2014 than in 2011, as are child care and kindergartens. The growth in the number of municipalities in which culture/sports take part are only relative and there is a substantial increase in the number of municipalities in which plan/environment and technical services are involved in intersectoral work groups. This is a positive finding according to the national policy goal of integrating health promotion into plans and it indicates that this is a process in progress.

Municipality 1 is in the forefront as the focus group and contends that:

The leader of the planning agency is the most important health promotion worker in the municipality. (Municipality 1)

Municipality 4 is in their fourth round of integrating health promotion in the Action Program:

It is a common understanding among us working in the organization [that health promotion is to be integrated into plans] and it is anchored in the administration, with the chief executive officer, the mayor and assistant executive officers. Health 
promotion is to be mirrored in the planning system, the master plan and action plans. (Municipality 4)

The second indicator for a HIAP approach is whether or not the municipality has employed a public health coordinator. In 2004 a program was launched providing municipalities who entered into health promotion partnerships with the county councils with economic support. The funding was part of a partnership program implemented by the Ministry of Health and Care Services. Municipalities were advised to use some of their funding to employ public health coordinators; $74 \%$ of municipalities had employed a coordinator in 2011 and $85 \%$ had done so by 2014 .

The HIAP perspective on public policies highlights how health is to be a responsibility not only for the health sector, but also for the whole of local government and its administration. And it is to include health in plans as stated by the PHA. Therefore it is of importance in which department the public health coordinator is located. If the coordinator is located in the health sector, it is not possible to have the necessary overview on the totality of policies carried out in municipalities. An employee in the chief executive officer's staff, on the other hand, could have such opportunities, as could an employee in the planning department as planning is to cover all services.

Table 3

The Department in which the Leader - the Public Health Coordinator - Works, in Percentages with Numbers in Parentheses. $N=2011: 209 ; 2014: 237$

\begin{tabular}{|l|l|l|}
\hline Year / Department of nearest leader & 2011 & 2014 \\
\hline Chief executive officer & $33,5(70)$ & $27(65)$ \\
\hline Culture & $12(26)$ & $9(22)$ \\
\hline Health & $46(96)$ & $36(85)$ \\
\hline Children and youth & $5(10)$ & $2(5)$ \\
\hline Planning & $3(7)$ & $7(16)$ \\
\hline Others & - & $19(44)$ \\
\hline
\end{tabular}

More respondents answered this question in 2014 than in 2011, but there has not been any substantial growth in those answering they have employed a public health coordinator. Nor has there been any growth within any department besides "others". On the other hand, there has been a reduction of public health coordinators in all departments except for planning in which there is a $4 \%$ increase from $3 \%$ to $7 \%$. Most of the focus groups had views on the localization of the public health coordinator. In Municipality 6 the focus group discussed the usefulness of having a public health coordinator:

It is not decided where to locate it. But it is clear that it must be located centrally in the organization, it has to be a position that can bridge between services, because we are talking about the technical services, among others. So the coordinator must be more centrally located, than in a department unit. (Municipality 6)

In Municipality 2 the public health coordinator position, also a full-time position, was recently established and the focus group reasoned about it the same way: 
My position is located within the chief executive officer's staff, and my leader is the director of the department of children, youth and culture. Organizational location is important when the political and administrative anchoring of public health is considered ... to raise awareness and ensure responsibility. (Municipality 2)

To have responsibility for overview over services and at the same time combine service provision and strengthen local development was a goal in Municipality 3:

We reorganized last year and the public health coordinator was moved to a unit that works with local development. Those working with local development, planning, environment, agriculture and public health were brought together in the same unit labeled the "local development unit". .... We are to work with local development, planning and strategies - measures that cover the whole municipality. (Municipality 3)

\section{Social inequalities}

As municipalities are responsible for the provision of most services to individuals as well as the local area development there are opportunities for them to reduce social inequalities in health. In 2011 we asked if the reduction of social inequalities in health was a goal for the work in municipal service providing agencies. Table 4 shows what agencies and in how many municipalities this was considered a goal.

Table 4

Municipalities in which there was a Goal of Reducing Social Inequalities in Health Among Units Providing Services, in Percentages with Number in Parentheses. $N=269$

\begin{tabular}{|l|l|}
\hline Service-providing agency & Percent consider this a goal \\
\hline Child health center & $43(117)$ \\
\hline School health service & $41(110)$ \\
\hline Social care & $37(99)$ \\
\hline Youth health service & $34(91)$ \\
\hline Kindergartens & $31(82)$ \\
\hline Mental health & $30(81)$ \\
\hline Schools & $27(74)$ \\
\hline Child care & $27(74)$ \\
\hline Sports & $20(53)$ \\
\hline Culture & $19(52)$ \\
\hline GPs & $14(39)$ \\
\hline Plan/environment/technical & $6(16)$ \\
\hline
\end{tabular}

As Table 4 shows, respondents most often consider services provided by the child health centers to have the reduction of social inequalities as a goal. Services providing health and social care also have quite high scores, even though no service scores more than $43 \%$. Schools and child care are not considered to a great extent to have the reduction of social inequalities as a goal, even though these are established goals in Norwegian educational policies. This observation made us question the understanding of the term social inequalities held by municipalities. Many municipalities consider that the sports, culture, primary health 
care, and planning/environment/technical departments do not have a role in reducing social inequalities in health.

In 2014 the question was posed a bit differently: As you consider it, is the municipality capable of reducing social inequalities in health? Of 272 municipalities $51 \%$ answered yes; $18 \%$ want to strengthen general welfare services; $34 \%$ will carry out targeted measures for vulnerable groups; and 43\% will combine the two to accomplish this goal. In 2014 we were also interested in knowing if distribution or redistribution between social groups was prioritized. Table 5 shows the distribution of responses.

Table 5

Presence of Priorities of Distribution/Redistribution of Resources amongst Social Groups, in Percentages with Numbers in Parentheses. $N=264$

\begin{tabular}{|l|l|}
\hline Priorities in: & Municipalities \\
\hline The master plan & $41(109)$ \\
\hline Agency activity plans & $44(116)$ \\
\hline Proceedings for political decisions & $38(99)$ \\
\hline Measures for health promotion and prevention & $71(187)$ \\
\hline
\end{tabular}

In the Master Plan local governments outline their long-term economic priorities. Our results indicate that local governments are slowly adopting the understanding that they are in fact capable of reducing social inequalities in health. The interviews support these findings, and indicate that municipalities implement health promotion measures, including universal as well as targeted measures to reduce social inequalities. In Municipality 1 it was described as a challenge that the children of poor families did not take part in any sports activities. The members of the focus group reasoned as follows:

We have families that are really poor. I think there are more inequalities in society than before. ... To reduce inequalities you need to offer a plethora of activities for children and youth. Not all can play football and to do biathlon is very expensive. ... We do have a plethora of activities, but they are not free. (Municipality 1)

The members of the group concluded that this was not in the hands of the municipality, and that national agencies were responsible to help out the children in these families.

In Municipality 3 the members of the focus group were aware of poverty among children. Their solution was to establish measures that could help families. The municipality had established a depot for sports equipment to be lent to children and their families. Kindergartens and schools were to be used to give children an opportunity to try out different activities. The municipal focus on this was a result of the national program to combat poverty. The local branch of this program was perceived as involving HIAP and intersectoral work and the children of mentally ill and drug addicted parents received special attention. In Municipality 4 the focus group pointed to a project to engage all children and youth, especially children from poor families, in activities that were funded by the local government and voluntary organizations, including a sports organization. In Municipality 6 the focus group had some other views: 
I think it is important to focus on the universalistic measures for children and youth. We need to economically support sports and other organizations and to keep our youth clubs. .... They are important for youth who don't take part in organized activities and important social meeting places. ... We also have three youth contacts [positions established to work according to the youth clubs]. (Municipality 6)

Even though the municipality experienced financial cutbacks the youth clubs and contacts were prioritized.

All municipalities were aware of a rather high level of school dropouts from upper secondary schools and that this had to be tackled at the lower levels in the primary and lower secondary schools. Some of the municipalities expressed helplessness responding to this challenge, but Municipality 6 had found their way around by working with youth in the youth clubs. In Municipalities 3 and 5 the work to reduce dropouts were systematized and done in collaboration with the county council. They had started health promoting kindergarten and school programs to focus the inclusion of children and get parents to know each other. A special program of parental support was adopted and every employee working with children and youth was to know it and take part:

We work universally and we also direct our work at vulnerable parents. ...We have a parental support coordinator; we have counselors within mental health and drug/alcohol, in kindergartens, culture and schools. We reach out broadly to reach the actual parents. The thought is that we will make parents more resilient and able to take care of their children. This will contribute to a better community. (Municipality 5)

We have worked very close to kindergartens and they have started to conduct conversations with parents when children start in kindergartens. In the conversations they focus mental health, risk of violence, drug and alcohol. We see great changes in what we accomplish. ... We have established robust transition procedures from kindergartens to schools. (Municipality 3)

\section{Funding}

Before the implementation of the PHA there was no earmarked funding from Central government for health promotion at the local level. In 2011, when the first survey was sent, we therefore asked how local governments funded their health promotion activities. Of 269 respondents that answered the question, $47 \%$ indicated they funded it, to a great extent, themselves. Table 6 shows the percentage of municipalities receiving funding from the county councils and the regional offices for the Ministry of Health and Care (regional state).

\section{Table 6}

The Share of Municipalities Receiving Funding from County Councils and the State, in Percentages with Numbers in Parentheses. $N=$ 2011: 269; 2014: 441

\begin{tabular}{|l|l|l|}
\hline Year / Funding agency & 2011 & 2014 \\
\hline Received funding from County Councils & $28(75)$ & $37(162)$ \\
\hline Received state funding & $6(17)$ & $44(195)$ \\
\hline
\end{tabular}


As was described above, a partnership and funding program was established in 2004 and municipalities could enter into partnerships with county councils and receive some small funding. Many used this to employ a public health coordinator. In Municipality 5, the members of the focus group reasoned about project funding as follows:

I have been a bit preoccupied by this project funding. It looks like it is a method used quite actively here... it has a lot of advantages but some challenges as well. One is: what do you do when the funding ends? The second is: how do you ensure that those involved in fact change their practice when projects end? (Municipality 5)

In Municipality 6 the members of the focus group reflect on this:

We fund a lot with project money. That is good for temporary programs and projects, but the challenge is to take it to ordinary operation. (Municipality 6)

In Municipality 4, they are aware that project funding is not necessarily in line with the goals of the PHA that state that the need for health promotion measures and interventions should be based in a defined municipality need for measures:

We like to believe that, when we start new measures, they emanate from a defined need. Often there is a national or regional program but we are more conscious that measures must be linked together so that it belongs [to an agency in the municipality administration] and not just pops up because oh, there was some money. (Municipality 4)

Municipalities are not happy with this way of funding as it makes their health promotion policies and measures dependent on the interests of actors outside the municipality. It might jeopardize the municipal competence on health promotion as it is built up during the implementation of projects and often have to be transferred to other functions or even laid off when projects end (Helgesen et al., 2014).

\section{Discussion}

The aim of this paper has been to answer the question of how municipalities can reduce social inequalities and level the social gradient in health among families with children. Norwegian National government policies have a strong focus on reducing social inequalities, and in the Public Health Act this is an overall aim. According to the Act, this should be achieved by intersectoral action at all administrative levels - a "Health in all Policies approach”. National steering mechanisms to achieve this are many, and laws and regulations as well as monitoring and funding are in use to make municipalities comply with national policy goals. County councils are given responsibility to guide municipalities within their area in the right direction but local governments have been given the most important role in implementing this ambitious policy.

In the Norwegian context this is quite logical, since the municipalities are responsible for the services that might contribute to achieving these aims: primary health care, social services, child day care, and primary and lower secondary school. Nevertheless, the Norwegian local government is embedded in a system of multilevel governance, which makes the implementation of the policy quite complex. When we look at the municipalities overall, it 
is obvious that they are in different places when it comes to implementing public health and health promotion policies. For some, the PHA is long-standing and they have been working to include health in plans and establish intersectoral working groups for many years and the inclusion of health in plans has been well established. These municipalities have worked stepwise to reach their level of inclusion of health in plans and most of them have started by developing a theme plan on public health and health promotion policies and measures.

Over time, these policy areas are included in the general planning system of municipalities: the Master Plans, Action Programs, and Spatial Plans, in this order. Including public health and health promotion in Action Programs is important to ensure that it is prioritized politically and even financially. Still, the inclusion of health promotion in the Spatial Plan is the most important as it is the plan that is legally binding. This is a positive development as it anchors public health and health promotion within the decision-making realms of local government.

Whether or not the inclusion of health in plans is a result of intersectoral collaboration is not yet clear, and our preliminary analyses can only suggest a connection. Our findings suggest that the dilemma of vertical budget control as opposed to horizontal and intersectoral collaboration is not solved in many municipalities. The responsibility for public health and health promotion is, to a large degree, still left to the health sector, including the public health coordinators (Helgesen \& Hofstad, 2012, Helgesen et al., 2014). From this location, very remote from the level where decisions are made, the public health coordinator is not in the position to have an overview of local determinants for health, or the municipal needs for public health measures. Furthermore, placing these positions within the health services does not facilitate collaboration with other service-providing agencies in order to implement policies or include health in plans. To comply with the PHA and develop their overview of local determinants, municipalities must consider employing a public health coordinator as well as locating this position in the municipal administrative organization. By localizing the coordinator with the chief executive leaders' staff or in the staff of the planning agency, the opportunities to actually have a coordinating role increases, and would give the coordinator some authority in the municipal administrative organization. To have a specialized function to coordinate will also be important in order to fulfill obligations to complete the health overviews and collaborate with the county and actors from civil society. We argue that this is the most efficient way to include health in local government plans.

To increase the priority of a Health in all Policies approach, there needs to be explicit support - and even political pressure - from the National government. Our findings indicate that funding is important to incentivize municipalities to take on the new challenges in public health work. Funding is always a strong incentive to prioritize health, and so far the funding to the municipalities following the Public Health Act has been scarce. Coordinated action at the national level, also expressed in coordinated funding, may be an important tool to initiate a process in which the municipalities give higher priority to developing a HIAP approach to health promotion.

The main aim of Norwegian policy is to provide equal opportunities for all citizens to achieve the same level of health and well-being. Given the large differences between the municipalities, this is not currently the case. Our findings indicate that the municipalities meet the challenges of the new Act differently. In particular, how they meet the expectations that they should contribute to levelling the social gradient in health seems to vary, especially how this problem is conceptualized. 
The Norwegian welfare state is to a wide extent built on universal measures, the core of these is access for all and redistribution among social groups. Marmot (2010), states that the principle of "proportionate universalism" is important to level the social gradient. According to Marmot, the basic principle should be universal measures, but some groups will need extra attention and support. The health promoting kindergarten and schools projects, as well as projects to ensure access to sports activities are results of the national plan to combat poverty. The main aim of these policies is that they in the long run will prevent school drop out by focusing on the inclusion of all children and their parents in kindergartens, schools, and sports activities. These policies have been developed by several ministries but implemented locally by municipalities as projects. The measures combine universal and targeted strategies and they also meet the health equity principle in the PHA. There seems to be agreement in the municipalities on this principle, but there also seems to be different sources of funding for the different types of services.

While the regular, universal services are funded on a permanent basis, the services aimed at improving the situation for disadvantaged groups are targeted, time limited, and often project funded. This means that the municipalities have to "run after the funding" which come from many different sources. To secure sustainability and ensure that the objectives of levelling the social gradient are met, measures addressing the social determinants of health should be provided with long-term, stable funding.

\section{Conclusion}

Municipalities have a plethora of possibilities to reduce social inequalities and level the social gradient in health for children and families. This can be done first and foremost by making an overview of the health and living conditions of their citizens, and including this overview in planning and decision-making, thus using their service-providing agencies to assure universal and high quality services to their citizens. The National government has one important tool to oversee that the policy is being implemented through audits of the municipalities' plans. Still, the municipalities have a high degree of freedom in how they will implement the policy. Our findings show that all municipalities are still not in line with national government goals. The common denominator of the municipalities in which we have conducted focus group interviews is that extra funding through national and county municipal targeted programs is the most important factor for increased activity to reduce social inequalities. 


\section{References}

Baldersheim H., \& Ståhlberg, K. (2002). Guided democracy or multi-level governance? New trends in regulatory regimes in central-local relations in the Nordic countries. Local Government Studies, 28, 74-90.

Dahl, E., Bergsli, H., \& van der Wel, K. (2014). Social inequalities in Norway: A Norwegian knowledge overview. Oslo: University College of Oslo and Akershus.

Directorate of Health. (2010). Public health - The road to good health for everybody, Oslo: Directorate of Health.

Directorate of Health. (2012). Policy report on public health. Oslo: Directorate of Health.

Esping-Andersen, G. (1990). The three worlds of welfare capitalism. Cambridge, UK: Polity Press.

Esping-Andersen, G. (2009). The incomplete revolution: Adapting welfare states to women's new roles. Cambridge, UK: Polity Press.

Fallet E., \& Saglie, I. L. (2013). Land use planning in municipalities In N. Aarsæther, E. Fallet, T. Nyseth, \& R. Kristiansen (Eds.), Challenges for Norwegian planning. knowledge, sustainability, and democracy (pp. 58-101). Oslo: Cappelen Damm.

Fosse, E. (2009). Norwegian public health policy - Revitalisation of the social democratic welfare state? International Journal of Health Services, 13(2), 287-300. http://dx.doi.org/10.2190/hs.39.2.d

Fosse, E. (2012). Norwegian experiences. In D. Raphael (Ed.), Tackling health inequalities: Lessons from international experiences (pp. 185-208). Toronto: Canadian Scholars' Press Incorporated.

Fosse, E. (2013). Norwegian policies to reduce poverty. Social Alternatives, 32(1), 31-35.

Fosse, E., Bull, T., Burström. B., \& Frtitzell, S. (2014). Family policy and inequalities in health in different welfare states. International Journal of Health Services, 44(2), 233251. http://dx.doi.org/10.2190/hs.44.2.c

Hanssen, G. S., \& Helgesen, M. K. (2011). Multi-level governance in Norway: Universalism in elderly and mental health care services. The International Journal of Sociology and Social Policy, 31(3-4), 160-172. http://dx.doi.org/10.1108/01443331111120609

Helgesen, M. K. (2012). Can health and health behaviour be governed? Public health as a governance theme in the state-local relation. In G. S. Hanssen. J. E. Klausen, \& J. E. O. Langeland (Eds.), Regional Norway 1950-2050. Are regions accommodated to the challenges of the $21^{\text {st }}$ century? (pp. 255-279). Oslo: Abstrakt Publishers.

Helgesen, M. K., \& Hofstad, H. (2012). Regional and local public health. Resources, organization and coordination: A baseline. NIBR report 2012/13. Oslo: Norwegian Institute for Urban and Regional Research. 
Helgesen, M. K., \& Hofstad, H. (2014). Determinants in Norwegian local government health promotion - Institutional perspectives. In J. J. Kronenfeld (Ed.), Research on the sociology of health care, volume 32 - Technology, communication, disparities and government options in health and health care services (pp. 143-180). Bingley, UK: Emerald Group Publishing Limited. http://dx.doi.org/10.1108/s0275-495920140000032019

Hofstad, H. (2011). Healthy urban planning: Ambitions, practices and prospects in a Norwegian context. Planning Theory and Practice, 12(3), 387-406. http://dx.doi.org/10.1080/14649357.2011.617498

Hooge, L., \& Marks, G. (2003). Unraveling the central state, but how? Types of multi-level governance. American Political Science Review, 97(2), 233-243. http://dx.doi.org/10.1017/s0003055403000649

Kjelvik, J. (2012). Health and environment of children and youth: Chosen indicators on social and environmental factors for children and youth. Report 12-2012. Oslo/Kongsvinger: Statistics Norway.

Leppo. K., Ollila, E., Peña, S., Wismar, M., \& Cook, S. (2013). Health in all policies: Seizing opportunities, implementing policies. Helsinki: Finnish Ministry of Social Affairs and Health.

Lundberg, O. (2009). How do welfare policies contribute to the reduction of health inequalities? Eurohealth, 15(3), 24-27.

Marmot, M. (2007). Achieving health equity: from root causes to fair outcomes. Lancet, 370 (9593), 1153-1163. http://dx.doi.org/10.1016/s0140-6736(07)61385-3

Marmot, M. (2010). The Marmot review: Fair society, healthy lives. Strategic review of health inequalities in England post-2010. London: University College London Institute of Health Equity.

Melkas, T. (2013). Health in all policy as a priority in Finnish health policy: A case study on national health policy development. Scandinavian Journal of Public Health, 41(3), 328. http://dx.doi.org/10.1177/1403494812472296

Ministry of Health and Care Services. (2011). PHA public health act, no. 29, 24-06-2011. Oslo: Ministry of Health and Care Services.

Ministry of Labour and Social Inclusion. (2006). Action plan to combat poverty. Oslo: Ministry of Labour and Social Inclusion.

Ministry of Local Government and Regional Development. (2012). Municipal structure. Oslo: Ministry of Local Government and Regional Development.

Osborne, S. P. (2010). Introduction: The (new) public governance: a suitable case for treatment? In S. P. Osborne (Ed.), The new public governance? Emerging perspectives on the theory and practice of public governance (pp. 1-16). New York: Routledge. http://dx.doi.org/10.4324/9780203861684 
Östergren, M. M., \& Barnekow, V. (2007). Child and adolescent health and development in a European perspective: A new WHO strategy. Danish Medical Bulletin, 54(2), 150152.

Popham, F., Dibben, C., \& Bambra, C. (2013). Are health inequalities really not the smallest in the Nordic welfare states? A comparison of mortality in 37 countries. Journal of Epidemiology and Community Health, 67(5), 412-418. http://dx.doi.org/10.1136/jech-2012-201525

Ramsdal, H., \& Skorstad, E. (2004). Privatizing from the inside. Bergen: Fagbokforlaget.

Sellers, J. M., \& Lidström, A. (2007). Decentralization, local government, and the welfare state. Governance: An International Journal of Policy, Administration, and Institutions, 20(4), 609-632. http://dx.doi.org/10.1111/j.1468-0491.2007.00374.x

Sørensen, E., \& Gjelstrup, G. (2007). Introduction. In E. Sørensen \& G. Gjelstrup (Eds.), Public administration in transition: Theory, practice, methodology (pp. 21-34). Copenhagen: DJØF Publishing.

Sørensen, E., \& Torfing, J. (2005). Network governance: From government to governance. Fredriksberg: Roskilde Universitetsforlag.

Sørensen, E., \& Torfing, J. (2007). Governance networks research: Towards a second generation. In E. Sørensen \& J. Torfing (Eds.), Theories of democratic network governance (pp. 1-23). London: Palgrave. http://dx.doi.org/10.1057/9780230625006

Ståhl, T., Wismar, M., Ollila, E., Lahtinen, E., \& Leppo, K. (2006). Health in all policies: Prospects and potentials. Helsinki: Ministry of Social Affairs and Health, Finland and European Observatory on Health Systems and Policies Finnish Health Department.

Strand, M., \& Fosse, E. (2011). Tackling health inequalities in Norway: Applying linear and non-linear models in the policy making process. Critical Public Health, 21(3), 373381. http://dx.doi.org/10.1080/09581596.2010.492210

Tallarek, M. G., Helgesen, M. K., \& Fosse, E. (2013). Reducing social inequalities in health in Norway: Concerted action at state and local levels? Health Policy, 113(3), 228-235. http://dx.doi.org/10.1016/j.healthpol.2013.09.019 